\title{
Teaching anatomy using an active and engaging learning strategy
}

\author{
Keerti Singh ${ }^{1}$, Ambadasu Bharatha ${ }^{1}$, Bidyadhar Sa ${ }^{2}$, Oswald Peter Adams ${ }^{1}$ and Md. Anwarul Azim Majumder ${ }^{*^{*}}$ (D)
}

\begin{abstract}
Background: Various evidence-based and student-centered strategies such as team-based learning (TBL), casebased learning $(\mathrm{CBL})$, and flipped classroom have been recently applied to anatomy education and have shown to improve student engagement and interaction. These strategies shift the focus of teaching from knowledge transmission to knowledge construction by students and encourage the use of tasks. This study discusses the use of an active and engaging learning strategy to teach the musculoskeletal system to Year 1 MBBS students (Faculty of Medical Sciences, The University of the West Indies, Cave Hill, Barbados) and examines the correlation between assessment modalities and student performance.

Methods: The "Active and Engaging Learning Strategy" was used to assess student learning in the form of oral presentations. Students had presentations on muscle attachments, muscle actions, blood and nerve supply, and applied anatomy of the limb musculature. Questions on the limbs (Locomotor System) were included in pre and postpresentation spotters, in-course assessments, and final examinations. Percentages, paired t-test, independent sample ttest, and zero-order correlations were performed to confirm the results for the different objectives of the study.

Results: The main modes of presentation chosen were poems (37.1\%), followed by stories (21.2\%), songs (11.4\%), and skits (10.6\%). The majority of students (84\%) found the strategies beneficial and recommended such sessions for future cohorts (92\%). Students achieved significantly better scores in post-presentation spotters $(p<0.01)$ and the marks of incourse and final examinations also showed significant improvement $(p<0.01)$.
\end{abstract}

Conclusion: Our study highlighted that the active and engaging learning strategy can be used as an effective learning tool in anatomy. Students were proactive in preparing the muscle presentations by utilizing their own creativity, curiosity, and intelligence. Further studies should be conducted using randomized controlled trials to assess the effectiveness of various learning strategies which could open a new door to medical education.

Keywords: Anatomy, Student-centred learning strategies, Active and engaging learning, Medical education, Barbados

\section{Background}

Anatomy is usually considered to be the 'foundation of medical sciences' [1-3], but it is also perceived to be an onerous and challenging subject in medical education [4]. Medical students need to acquire core anatomical knowledge to build a strong foundation for future clinical encounters and professional practice $[2,5]$. Traditionally, anatomy was considered to be a dull, labour-intensive subject, and was taught using surface learning approaches and rote memorization [6, 7]. However, the teaching of anatomy is undergoing an

\footnotetext{
* Correspondence: azim.majumder@cavehill.uwi.edu

${ }^{1}$ Faculty of Medical Sciences, The University of the West Indies, Cave Hill, Barbados

Full list of author information is available at the end of the article
}

evolutionary change with the adoption of modern philosophies, approaches, and effective teaching and learning strategies. An important point of concern is, anatomy teaching in the medical and other health professional education programmes is on the decline and 'has fallen below a safe level' in recent years $[2,8]$. Furthermore, anatomists face the recent pressures of the changing modes of medical education and assessment, with fewer contact hours and limited resources to teach an extremely diverse group of students with different sets of prior scientific literary levels, cultural backgrounds, and experiences $[9,10]$. Thus, it is important for anatomists to explore innovative and stimulating, engaging, creative, purposeful, multimodal means to

(c) The Author(s). 2019 Open Access This article is distributed under the terms of the Creative Commons Attribution 4.0 International License (http://creativecommons.org/licenses/by/4.0/), which permits unrestricted use, distribution, and 
encourage proactive and deep learning, and to develop long-term memory in students in order to improve student engagement and learning outcomes that align with their professional goals [3, 11, 12]. Though anatomy classrooms use a wide range of technology in the form of e-textbooks, models, CD-ROMs and simulations, engaging modern and alternative approaches in medical education has become an essential element today $[13,14]$. New strategies are emerging in anatomy teaching that incorporate technology, making learning interactive, student-centered, and more appealing to the general student body [13-15].

Learning anatomy with cadaveric dissection has become almost non-existent in most medical schools owing to the shortage in the number of cadavers compared to the growing student numbers [16]. In recent years, a paradigm shift from teacher-centered to a learner-centered approach has been observed in teaching and learning of anatomy using innovative and interactive instructional strategies and techniques $[2,5,13-15,17]$. Team-based learning, case-based learning (CBL), flipped lectures, peer teaching, computer-assisted learning, videos, simulations, and virtual interactive 3D images are a few examples of such approaches. These approaches make anatomy teaching interesting, interactive, and engaging, and help students with deep learning, effective retention, and application of the knowledge in the clinical context $[2,5]$. Moreover, these strategies also mitigate challenges associated with teaching anatomy such as a shortage of anatomists [18], lack of cadaveric materials $[13,16]$, and the excessive content in the anatomy curriculum $[1,8,9,19-21]$. As a result, the perception of anatomy learning has gradually changed from a dry, boring subject to an engaging and a fascinating subject as student-centered approaches are adopted to teach and assess the knowledge of anatomical structures [4].

Students must receive adequate and appropriate training in musculoskeletal anatomy because musculoskeletal complaints are found to be the most common presenting illnesses in primary care settings in many developed and developing countries [22]. Moreover, studies have demonstrated significant deficits in musculoskeletal education, resulting in a low competency in performing musculoskeletal physical examinations, and a lack of confidence in interpreting the findings $[23,24]$. In the United States Medical Licensing Examination (USMLE) Step 2 Clinical Skills Examination, performance of the musculoskeletal physical examination is significantly poorer in comparison to physical examination performance in other domains [25]. To reduce these shortcomings, innovative approaches must be used in undergraduate medical education to improve the quality of teaching and learning of the musculoskeletal system [26].
In order to improve teaching of the musculoskeletal system in anatomy to Year 1 MBBS students of the Faculty of Medical Sciences (FMS), The University of the West Indies (UWI), Cave Hill Campus, Barbados, we designed an 'active and engaging learning strategy' based on the definitions of active learning by Bonwell \& Eison [27] and Felder and Brent [28]. Bonwell \& Eison [27] defined active learning as "anything that involves students in doing things and thinking about the things they are doing", and Felder and Brent [28] mentioned active learning as "anything course-related that all students in a class session are called upon to do other than simply watching, listening, and taking notes". The "Active and engaging learning strategy" shifts the focus of teaching away from knowledge transmission to knowledge construction by students and encourages the use of tasks, interactive presentations, assignments, and creative activities. In this study, the aim was two-fold: (i) to report students' experience with the student-centered 'active and engaging learning strategy' introduced to teach the musculoskeletal system, and (ii) to determine if there was a relationship between assessment modalities and student performance.

\section{Methods}

\section{Ethical approval}

Ethical approval for the study was obtained from the Institutional Review Board (IRB of The UWI Cave Hill Campus and the Ministry of Health, Barbados (IRB No: 170203-B).

\section{Study participants and settings}

The study was conducted in the 2017/2018 academic year. Sixty-six first-year students registered in the Locomotor System course were invited to participate in the study. The Locomotor System course is a 13-week course taught in semester one, Year 1 of the MBBS programme. It is a part of an integrated series of courses in the pre-clinical phase ( 3 years) of the MBBS programme (5 years). This course is usually delivered utilizing multimodal approaches such as lectures, seminars, tutorials, demonstrations, laboratory practicals, case/problem-based learning, simulations, use of multimedia, and the University's E-learning Course Management System (Moodle). Before the introduction of the active and engaging learning strategy, anatomy teaching was mostly done using didactic lectures by PowerPoint delivery, prosected specimens, CD-ROMs, and CBL.

Grading of the Locomotor System course consisted of: (1) Continuous assessments (40\%) comprising of spotters $(10 \%)$, presentations using the active and engaging learning strategy (10\%), and a mid-term exam (20\%), and (2) a final exam (60\%) using multiple choice questions (MCQ) and short answer questions (SAQs). 


\section{Study design}

\section{a. Active and engaging learning and assessment strategies}

We developed an 'active and engaging learning strategy' based on Bonwell \& Eison's [27] and Felder and Brent's [28] active learning concepts and introduced it in the Locomotor System course to teach the musculoskeletal system in Semester 1. Each student was invited to create upper (UL) and lower limbs (LL) muscle presentations using a poem, story, song, skit, video, poster, PowerPoint presentation etc., which would be engaging and interesting to their peers. Student performance in the pre-presentation spotter assessment was compared with the post-presentation spotter assessment, mid-term, and final examinations to assess the overall effectiveness of the active and engaging learning strategy.

\section{b. Upper limb muscles presentation \\ i. Pre-presentation spotter (week 7)}

Students were given an unscheduled UL anatomy spotter exam in week 7 to assess their baseline knowledge of the muscles. There were $20 \mathrm{SAQs}$ in the spotter. These pre-test marks did not contribute to the final grades for the course. At the end of the pre-test, students were allocated muscles to be the subject of their presentations in week 8 .

Students were randomly divided into two batches Group A and Group B (33 students in each) for muscle presentations in the anatomy lab. Fifty-one muscles were identified for presentation. Each student was allotted one or a maximum of two muscles. The time limit for each presentation was 5 minutes. Students were instructed to prepare a presentation using an active and engaging learning strategy of their choice (poem, song, game, skit, role play, video, drawing, monologue, etc.) highlighting the attachments, actions, blood, nerve supply, and clinical anatomy of the muscles allocated to them. They were given a short briefing to introduce the options for the various modes of muscle presentations and regarding the five main scoring criteria included in the scoring rubric. They were also advised to discuss the various presentation modes with their seniors (Year 2 MBBS students) who underwent a similar exercise in the previous year but were not formally assessed.

\section{ii. Upper limb muscles presentation session (week 8)}

Students had their upper limb muscle presentations using a pre-designed scoring rubric (Additional file 1) explaining the mark distribution for creativity, relevance, accuracy, completeness, and confidence of the student (each component was worth 2 marks for a maximum score of 10). These marks were worth $5 \%$ of the final course grade.

\section{iii. Upper limb post-presentation spotter (week 9)}

The post-presentation spotters for both Group A and Group B were held in week 9 (1 week after the UL presentations) on the same day for both groups. It contributed 5\% of the final course mark for the students. The spotter included 20 SAQs related to the muscles presented in week 8 .

\section{c. Mid-term exam (week 9)}

A mid-term examination consisting of $40 \mathrm{MCQ}$ questions and contributing $20 \%$ of the final course mark was also held in week 9 .

\section{d. Lower limb muscles presentation session (week 11)}

There were 49 muscles identified for presentation. The same procedures were used in the allocation and presentation of the muscles as in Week 9. This presentation was also worth $5 \%$ of the final course grade.

\section{e. Lower limb post-presentation spotter (week 12)}

The LL spotters followed the same guidelines as UL. The only difference was, there was no pre-presentation spotter. There were 25 SAQs in the spotter, these were related to the muscles presented in week 11. The post-presentation spotter contributed $5 \%$ of the final course marks for the students.

\section{f. Final examination:}

Final examinations were held in week 14. The exam paper consisted of $50 \mathrm{MCQs}$ and 4 SAQs testing knowledge of UL and LL muscles. The weighting of the exam was $60 \%$ of the final mark of the course.

\section{Feedback from the students (students' experience)}

An online questionnaire using Survey Monkey was used to collect data on the students' experience with the active and engaging learning strategy. The questionnaire consisted of six questions related to the muscle presentations; three were closed-ended and three open-ended questions. The questionnaire was developed by the authors and reviewed by experts from the anatomy and medical education departments.

\section{Statistical analyses}

All analyses were performed using SPSS 24 Statistical software. Percentages were calculated to ascertain the students' experience with the active and engaging 
learning strategy used for the muscle presentations. A paired $\mathrm{t}$-test was used to establish whether there was a significant difference between pre- and post-presentation performance, and an independent sample t-test was calculated, to discover whether there was a significant difference between Group A and Group B's performance in different components of assessment. Zero-order correlations were performed to determine whether any correlations existed between the UL post-presentation spotter (week 9), mid-term exam (week 9), LL post-presentation spotter (week 11), and final examination (week 14) scores.

\section{Results}

Modes of presentations used for active and engaging learning strategy

Sixty-six Year 1 students (response rate 100\%) attended the muscle presentation sessions using active and engaging learning strategies, spotters, and examinations. Attendance was mandatory in these sessions. Poems (37.1\%) were most frequently used in making the UL and LL presentations and this was followed by stories (21.2\%), songs (11.4\%), and skits (10.6\%) (See Table 1). Some of the poems, stories, songs, and skits are included in Additional file 2.

\section{Experience of students with active and engaging learning strategies}

Thirty-eight students (57.5\%) completed the anonymous online feedback questionnaire given after the final exam results. Eighty-four percent of the students reported that they benefitted from using the active and engaging learning strategy for their muscle presentations and 92\% recommended such sessions for future cohorts. Sixty-three percent agreed that the muscle presentations should include a social message as they were more receptive to such presentations, and this helped in better retention and recollection of facts. When asked about the most preferred method of presentation which helped students to retain and recall the gross anatomical concepts and terminologies, they identified poems (26\%), jingles (21\%), songs $(21 \%)$, skits (13\%), mimicry (8\%), games $(5.25 \%)$, and posters $(2.6 \%)$.

Students also found the active and engaging learning strategy to be helpful for the following reasons: encourages creativity, peer to peer interaction and research; active and memorable way to learn; integrated and quick way to gain knowledge; new modes of the presentations by peers made learning easy in a relaxed environment; and live presentations helped in long term memory and retention. The changes students wanted in the future were more time for preparation, competition/quizzes with prizes, and professional recording of presentations for future use.

\section{Relationships of active and engaging learning strategy with assessment modalities and students' marks}

All raw scores are converted to $100 \%$ and the mean scores for all the examinations are shown in Table 2. Comparison of pre-presentation spotter and post-presentation spotter scores of UL revealed that post-presentation scores significantly increased in comparison to pre-presentation $\left(\mathrm{t}_{65}=\right.$ 8.018, $p<0.01$ ). This suggests that the intervention strategy used contributed significantly to enhancing the students' learning. The Pearson correlation demonstrated a significant $(p<0.01)$ relationship between different modalities of assessment (Table 3). Further, it could be posited that there is a highly significant positive relationship between:

(i) Pre-presentation spotter (UL) and post-presentation spotter (UL)/mid-term/spotter (LL)/final course marks

(ii) Post-presentation spotter (UL) and mid-term/spotter (LL)/total course marks

(iii) Midterm and spotter (LL)/total course marks

(iv) Spotter (LL) and total course marks

Table 1 Different modes of presentation by the students

\begin{tabular}{|c|c|c|c|}
\hline Presentation modes & Upper $\operatorname{limb}$ muscles $N=66$ & $\begin{array}{l}\text { Lower limb muscles } \\
N=66\end{array}$ & $\begin{array}{l}\text { Total } \\
N=132\end{array}$ \\
\hline Poem & $19(29 \%)$ & $30(45 \%)$ & $49(37 \%)$ \\
\hline Story & $12(18 \%)$ & $16(24 \%)$ & $28(21 \%)$ \\
\hline Song & $7(11 \%)$ & $8(12 \%)$ & $15(11 \%)$ \\
\hline Skit & $10(15 \%)$ & $4(6 \%)$ & $14(11 \%)$ \\
\hline Monologue & $5(8 \%)$ & $3(5 \%)$ & $8(6 \%)$ \\
\hline PowerPoint & $3(5 \%)$ & $2(3 \%)$ & $5(4 \%)$ \\
\hline Riddle & $5(8 \%)$ & $0(0 \%)$ & $5(4 \%)$ \\
\hline Video & $3(5 \%)$ & $0(0 \%)$ & $3(2 \%)$ \\
\hline Game & $1(2 \%)$ & $0(0 \%)$ & $1(1 \%)$ \\
\hline Drawing & $1(2 \%)$ & $1(2 \%)$ & $2(2 \%)$ \\
\hline
\end{tabular}


Table 2 Student performance in examinations (N-66)

\begin{tabular}{lll}
\hline Examinations & Weightage & Marks (Mean \pm SD) \\
\hline Pre-presentation spotter (UL) & - & $54.5 \pm 18$ \\
Active and engaging learning presentation (UL) & $5 \%$ & $77.0 \pm 16.1$ \\
Post-presentation spotter (UL) & $5 \%$ & $67.9 \pm 13.6$ \\
Mid-Term Exam & $20 \%$ & $66.1 \pm 13.4$ \\
Active and engaging learning presentation (LL) & $5 \%$ & $72.3 \pm 16.4$ \\
Spotter (LL) & $5 \%$ & $67.9 \pm 13.1$ \\
Final Exam & $60 \%$ & $66.6 \pm 9.9$ \\
Total marks & $100 \%$ & $67.2 \pm 8.9$ \\
\hline
\end{tabular}

UL Upper limb, LL Lower limb

(v) Final examinations and total course marks. However, there was no significant relationship between final examinations scores and any of the modalities of assessment.

\section{Comparison of performance between student groups}

Table 4 shows the comparison of performance between two student Groups A and B. None of the findings were found to be statistically significant, which indicated that students were homogenous and randomly assigned to both the groups.

\section{Discussion}

The present study demonstrated that students found the active and engaging learning strategy beneficial. It helped them to use and apply knowledge in a constructive, active and interesting way, and to exploit their own creativity, curiosity and intelligence. Moreover, students achieved significantly better scores in post-presentation spotters $(p<0.01)$ and the marks of different modalities of assessment also showed a significant positive relationship $(p<0.01)$ possibly due to the adaptation of the active and engaging learning strategy. Many recent studies have used new complimentary technology-based innovative teaching techniques with clinically focused and diversified pedagogical approaches in basic science teaching to fill this gap [2, 3, 5, 17, 29]. The active and engaging learning strategy gives the student overall responsibility for and freedom to create presentations which are easy to understand, remember, and recollect for themselves and their peers [29]. Moreover, students gain confidence as they play the role of the teachers to their peers.

The students chose to use a number of visual, literary, and performing arts-related presentation approaches like poems, stories, songs, skits, monologues riddles, videos, PowerPoint presentations, games, drawings, posters, cartoons, etc. (Table 1, Additional file 2). One of the interesting observations was, very few students chose PowerPoint (3.9\%), which is considered to be a widely used presentation mode in medical education [30]. Studies have shown that using such approaches in medical education can improve medical students' critical, observational, and diagnostic skills [30, 31]. Essential humanitarian instincts and other generic skills (e.g. presentation techniques, communication skills, time management, creativity, etc.) should receive due attention in medical training because they offer many benefits in relation to medical practice later in professional life [32]. Recently, the role of the humanities in training medical students has been garnering recognition, especially the use of 'literature, art, creative writing, drama, film, music, philosophy, ethical decision-making, anthropology and history' [33]. Moreover, assessment strategies need to focus on evidence of achievement rather than the ability to regurgitate information, that is, assessment for, and not just of, learning [34]. Medical schools should put more emphasis on assessment tools that measure not just recall of facts, but the development of the desired competencies needed for future professional life [35].

Table 3 Correlations between different assessment modalities

\begin{tabular}{|c|c|c|c|c|c|}
\hline & Post-presentation spotter (UL) & Mid-term & Spotter (LL) & Final exam & Total marks \\
\hline Pre-presentation spotter (UL) & $0.653^{a}$ & $0.516^{a}$ & $0.653^{a}$ & $0.391^{a}$ & $0.550^{a}$ \\
\hline Post- presentation spotter (UL & & $0.732^{\mathrm{a}}$ & $1.000^{\mathrm{a}}$ & $0.443^{\mathrm{a}}$ & $0.688^{\mathrm{a}}$ \\
\hline Mid-Term & & & $0.732^{\mathrm{a}}$ & $0.355^{\mathrm{a}}$ & $0.719^{a}$ \\
\hline Spotter (LL) & & & & $0.443^{\mathrm{a}}$ & $0.688^{\mathrm{a}}$ \\
\hline Final Exam & & & & & $0.884^{\mathrm{a}}$ \\
\hline
\end{tabular}

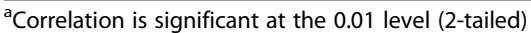

UL Upper limb, LL Lower limb 
Table 4 Comparison of performance between group A ( $\left.n_{1}=33\right)$ and Group B $\left(n_{2}=33\right)$

\begin{tabular}{|c|c|c|c|c|c|c|}
\hline & \multirow[t]{2}{*}{ Group } & \multirow[t]{2}{*}{ Mean \pm SD } & \multirow[t]{2}{*}{ t-ratio } & \multirow[t]{2}{*}{$p$-value } & \multicolumn{2}{|c|}{ 95\% Confidence Interval } \\
\hline & & & & & Lower & Upper \\
\hline \multirow[t]{2}{*}{ Pre-presentation spotter (UL) } & A & $57.35 \pm 15.18$ & \multirow[t]{2}{*}{1.31} & \multirow[t]{2}{*}{0.20} & -3.01 & 14.53 \\
\hline & B & $51.60 \pm 20.14$ & & & -3.03 & 14.54 \\
\hline \multirow[t]{2}{*}{ Active and engaging learning presentation (UL) } & A & $77.88 \pm 17.28$ & \multirow[t]{2}{*}{0.46} & \multirow[t]{2}{*}{0.65} & -6.14 & 9.78 \\
\hline & B & $76.06 \pm 14.99$ & & & -6.14 & 9.78 \\
\hline \multirow[t]{2}{*}{ Post-presentation spotter (UL) } & A & $68.40 \pm 14.28$ & \multirow[t]{2}{*}{0.28} & \multirow[t]{2}{*}{0.78} & -5.56 & 7.37 \\
\hline & B & $67.49 \pm 11.91$ & & & -5.57 & 7.38 \\
\hline \multirow[t]{2}{*}{ Mid Term } & A & $67.95 \pm 14.19$ & \multirow[t]{2}{*}{1.14} & \multirow[t]{2}{*}{0.26} & -2.80 & 10.31 \\
\hline & B & $64.19 \pm 12.41$ & & & -2.80 & 10.31 \\
\hline \multirow[t]{2}{*}{ Active and engaging learning presentation (LL) } & A & $71.21 \pm 14.74$ & \multirow[t]{2}{*}{0.52} & \multirow[t]{2}{*}{0.60} & -10.25 & 6.01 \\
\hline & $\mathrm{B}$ & $73.33 \pm 18.14$ & & & -10.26 & 6.01 \\
\hline \multirow[t]{2}{*}{ Spotter (LL) } & A & $68.40 \pm 14.28$ & \multirow[t]{2}{*}{0.28} & \multirow[t]{2}{*}{0.78} & -5.56 & 7.37 \\
\hline & B & $67.49 \pm 11.91$ & & & -5.57 & 7.38 \\
\hline \multirow[t]{2}{*}{ Final Exam } & A & $66.79 \pm 8.68$ & \multirow[t]{2}{*}{0.17} & \multirow[t]{2}{*}{0.86} & -4.48 & 5.33 \\
\hline & B & $66.36 \pm 11.12$ & & & -4.49 & 5.34 \\
\hline \multirow[t]{2}{*}{ Total } & A & $67.97 \pm 8.48$ & \multirow[t]{2}{*}{0.66} & \multirow[t]{2}{*}{0.51} & -2.93 & 5.84 \\
\hline & B & $66.52 \pm 9.32$ & & & -2.93 & 5.84 \\
\hline
\end{tabular}

UL Upper limb, LL Lower limb

In our study, more than one-fifth (21.2\%) of the students adopted the mode of storytelling in their presentations, which followed the most preferred choice 'poems' (37.1\%). Students also utilized other modes of presentations as shown in Table 1. According to Kieser et al., spontaneous storytelling approach nurtures reflective learning while students work on their clinical anatomy problems [36]. Poetry was also found to relate well to medicine, where the physician first grasps and then controls the reality of the human predicament [37]. Medical educators can learn about the emotional reactions and concerns of students through their reflective writing in general and poetry in particular [38]. Creative writing offers nurses and doctors a hands-on experience to understand the patient's hesitancy and degree of difficulty in telling their story and to appreciate the role of feedback, editing, and rewriting in formulating a well-written clinical history [39]. Dolberry (2011) reported the benefits of writing skits and role-playing in a student-guided assignment where instructors transfer more responsibility and independence in choosing to present the information students learnt in the course. Creative writing and role-playing may help students retain course information, expand their knowledge and relate to content in a meaningful way [40].

Many studies at the pre-university level have demonstrated positive outcomes in student perceptions, and, in some cases, class performance, through the use of educational songs and music videos in food service and food safety [41], sciences [42], and natural history [43] curricula. Apart from aiding memorization, songs may potentially improve learning by helping students feel relaxed and welcome in stressful settings, and also by engaging students through multiple modes (verbal vs. nonverbal) and modalities (auditory vs. visual vs. kinesthetic). Game-based learning offers students the opportunity to improve and maintain information literacy skills, particularly information seeking and critical appraisal, in an engaging way [44]. Medical theatre utilized multisensory hands-on learning (e.g. a story, a play script, a poem, a song, use of Play-doh, body painting, a game, a monologue, cartoons, comics, or through role play) and found it to be effective in encouraging active and engaging learning [11].

Change in medical education is a worldwide agenda and many medical schools have witnessed experimentation and experienced challenges [45]. Similarly, an active and integrated approach to the teaching of anatomy has been emphasized in a modern medical curriculum [46]. Many studies have demonstrated the benefits of multimodal teaching modalities by integrating modernized digital technology, dissection, and problem-based learning in anatomy and other fields [46]. However, one of their main drawbacks is that they deliver one-sided information through passive learning, and encourage rote memorization of names and structures; as a result, students fail to develop critical thinking skills [47]. A well-designed active and engaging learning strategy carried out in a suitable and relaxed environment can help to overcome these challenges and limitations. 


\section{Limitations}

Our study has a number of limitations. Firstly, the study had a small sample size; therefore, caution needs to be taken in generalizing the data to other settings. Secondly, the effectiveness of the individual modes of presentations was not evaluated. Lastly, the students' marks may have been influenced by other teaching strategies (lectures, practicals, etc.) or by students' previous knowledge. Further studies should be conducted utilizing multiple campuses of The UWI to explore the effectiveness of the various modalities of the active and engaging learning strategy in anatomy, and in other disciplines as well.

\section{Conclusion}

Our study highlighted that the active and engaging learning strategy can be used as an effective learning tool to teach anatomy. This strategy helped students to take an active role in learning and utilizing their own creativity, curiosity, and intelligence. The core curriculum for musculoskeletal anatomy needs to be identified for undergraduate and post-graduate curricula, and innovative teaching techniques should be adopted for effective and interactive learning. As research into the usefulness and evaluation of active and engaging learning strategy is still in its infancy in anatomy teaching, further research to assess the effectiveness of each modality of the active and engaging learning strategy would provide a better approach to teaching anatomy. Use of randomized controlled trials to assess the effectiveness of various learning strategies could open a new door to medical education.

\section{Additional files}

Additional file 1: Scoring Rubric for Presentations. (DOCX $15 \mathrm{~kb}$ )

Additional file 2: Selected Presentations by the students. (DOC 393 kb)

\section{Abbreviations}

CAL: Computer-assisted learning; CBL: case-based learning; FMS: Faculty of Medical Sciences; LL: Lower limbs; MBBS: Bachelor of Medicine and Bachelor of Surgery; MCQ: Multiple choice questions; SAQs: Short answer questions; TBL: Team-based learning; The UWI: The University of the West Indies; UL: Upper Limb; USMLE: United States Medical Licensing Examination

\footnotetext{
Acknowledgments

The authors wish to thank the students who participated in the active and engaging learning and made the sessions enjoyable, active and interesting. We extend our gratitude to Dr. Korah Belgrave (Lecturer in Linguistics and Communication studies, Department of Language, Linguistics and Literature, UWI, Cave Hill, Barbados) and Mrs. Allison Shepherd (PECH Tutor, CMSE, FMS, UWI, St Augustine, Trinidad and Tobago) for her assistance in reviewing this manuscript for English language and grammar. The authors would also like to thank Ms. Kiana Hall (Medical Laboratory Technologist), Ms. Keisha Mascoll (Medical Laboratory Technologist), and Ms. Janneve Broomes (Medical Laboratory Technician) for their cooperation and support in organizing the active and engaging learning sessions.
}

\section{Funding}

No funding was obtained for this study.

\section{Availability of data and materials}

The datasets of the current study are available from the corresponding authors on reasonable request.

\section{Authors' contributions}

KS conceived and designed the study and led data collection. All authors (BS, MAAM, OPA, KS, AB) were involved in analysing and interpreting the data. The manuscript was drafted by MAAM and KS with notable input from OPA, BS and AB. All authors reviewed and approved the final version and have agreed to be accountable for all aspects of the work including any issues related to accuracy or integrity.

\section{Authors' information}

KEERTI SINGH, MBBS, MS (Anatomy) is a Lecturer of Anatomy in the Faculty of Medical Sciences, The UWI Cave Hill Campus, Barbados. She teaches clinical anatomy, embryology and histology to the medical students in Phase 1. Her research interest is in medical education, gross anatomy, clinical anatomy, and male infertility.

AMBADASU BHARATHA, MSc, Ph.D. (Pharmacology) is a Lecturer of Pharmacology in the Faculty of Medical Sciences, The UWI, Cave Hill Campus, Barbados. He teaches pharmacology to the MBBS students in Phase 1. His research areas of interest are experimental pharmacology, obesity, diabetes, and cardiovascular pharmacology.

BIDYADHAR SA BA (Hons), MA, MPhil, Ph.D. (Education) is the Head of the Centre for Medical Sciences Education and Deputy Dean, Quality Assurance and Accreditation, Faculty of Medical Sciences, The UWI, St Augustine Campus, Trinidad \& Tobago. His main research interests include assessment in medical education, emotional intelligence, and empathy among health professional students and practitioners.

OSWALD PETER ADAMS BSC, MBBS, MSc, DM (Family Medicine) is the Dean of the Faculty of Medical Sciences, The UWI, Cave Hill Campus, Barbados. He is a Family Physician. His main research areas are chronic non-communicable diseases and sexually transmitted infections.

MD. ANWARUL AZIM MAJUMDER MBBS, MHPEd, PGDipHEcons, FHEA, Ph.D. (Medical Education) is the Director of Medical Education of the Faculty of Medical Sciences, The UWI Cave Hill Campus, Barbados. His main research interests are in medical/health profession education, health systems, and public health, and he has extensive experience in curriculum development, $\mathrm{HRH}$ management, and implementing faculty development programs in developed and developing countries.

\section{Ethics approval and consent to participate}

This study was approved by The University of the West Indies-Cave Hill/ Barbados Ministry of Health Research Ethics Committee/Institutional Review Board. IRB No: 170203-B. The IRB approval included an exemption for informed consent in the above-mentioned work.

\section{Consent for publication}

The IRB approval included an exemption for informed consent in the abovementioned work. However, written consent was obtained from study participants for publication of research data, students' works and/or any photos/ videos.

\section{Competing interests}

The authors declare that they have no competing interests.

\section{Publisher's Note}

Springer Nature remains neutral with regard to jurisdictional claims in published maps and institutional affiliations.

\section{Author details}

${ }^{1}$ Faculty of Medical Sciences, The University of the West Indies, Cave Hill, Barbados. ${ }^{2}$ Faculty of Medical Sciences, The University of the West Indies, St. Augustine, Trinidad and Tobago. 
Received: 19 November 2018 Accepted: 2 May 2019

Published online: 16 May 2019

\section{References}

1. Pujol S, Baldwin M, Nassiri J, Kikinis R, Shaffer K. Using 3D modelling techniques to enhance teaching of difficult anatomical concepts. Acad Radiol. 2016;23(4):507-16.

2. Tubbs RS, Sorenson EP, Sharma A, Benninger B, Norton N, Loukas M, Moxham BJ. The development of a core syllabus for the teaching of head and neck anatomy to medical students. Clin Anat. 2014;27:321-30.

3. Guimaraes B, Durado L, Tsisar S, Diniz JM, Madeira MD, Ferreira MA. Rethinking anatomy: how to overcome challenges of medical Education's evolution. Acta Medica Port. 2017:30(2):134-40.

4. Dimon T Jr. Anatomy of the moving body. A basic course in bones, muscles and joints. 2nd Ed. Berkeley, California: North Atlantic Books. 2008. p.280.

5. Smith CF, Finn GM, Stewart J, McHanwell S. Anatomical society core regional anatomy syllabus for undergraduate medicine: the Delphi process. J Anat. 2016;228:2-14.

6. Biggs J. Constructing learning by aligning teaching: constructive alignment. Teaching for quality learning at university: what the student does. 2nd ed. Buckingham. SRHE and open University Press; 2003.

7. Hopkins R, Regehr G, Wilson TD. Exploring the changing learning environment of the gross anatomy lab. Acad Med. 2011;86:883-8.

8. Ali A, Khan ZN, Konczalik CP, El Sayed S. The perception of anatomy teaching among UK medical students. Bul R Coll Surg Engl. 2015;97(9):397-400.

9. Tworek JK, Jamniczky HA, Jacob C, Hallgrímsson B, Wright B. The LINDSAY virtual human project: an immersive approach to anatomy and physiology. Anat Sci Educ. 2013;6(1):19-28.

10. Bergman EM. Discussing dissection in anatomy education. Prospect Med Educ. 2015:4:211-3.

11. Diaz CM. Innovation in anatomy teaching. Anat Sci Educ. 2013:155-73.

12. Ward PJ. First year medical students' approaches to study and their outcomes in a gross anatomy course. Clin Anat. 2011;24(1):120-7.

13. Kurt E, Yurdakul SE, Atac A. An overview of the technologies used for anatomy education in terms of medical history. Procedia Soc Behav Sci. 2013;103:109-15.

14. Torres K1, Torres A, Pietrzyk L, Lisiecka J, Błoński M, Bącik-Donica M, Staśkiewicz G, Maciejewski R. Simulation techniques in the anatomy curriculum: review of literature. Folia Morphol (Warsz). 2014;73:1):1-6.

15. Waight N, Chiu MM, Whitford M. Factors that influence science teacher's selection and usage of technologies in high school science classrooms. J Sci Educ Technol. 2014;23:668-81.

16. Chen D1, Zhang Q, Deng J, Cai Y, Huang J, Li F, Xiong K. A shortage of cadavers: the predicament of regional anatomy education in mainland China. Anat Sci Educ. 2018;11(4):397-402.

17. Singh $V$, Kharb P. A paradigm shift from teaching to learning gross anatomy: meta-analysis of implications for instructional methods. J Anat Soc India. 2013:62:84-9.

18. Dickman N, Barash A, Reis S, Karasik D. Students as anatomy near-peer teachers: a double-edged sword for an ancient skill. BMC Med Educ. 2017; 17(1):156.

19. BinDhim NF, Trevena L. There's an app for that: a Giude for healthcare practitioners and researchers on smartphone technology. Online J Public Health Inform 2015; 1:7(2):e218

20. Lee N-J, Chae S-M, Kim H, Lee JH, Min HJ, Park DE. Mobile- based video learning outcomes in clinical nursing skill education. Comput inform Nurs. 2016;34(1):8-16.

21. Lewis TL, Burnett B, Tunstall RG. Complementing anatomy education using three-dimensional anatomy mobile software applications on tablet computers. Clin Anat. 2014;27(3):313-20.

22. Siddharthan $\mathrm{T}$, Soares $\mathrm{S}$, Wang HH, Holt SR. Objective structured clinical examination-based teaching of the musculoskeletal examination. South Med J. 2017;110(12):761-4.

23. Day CS, Yeh AC, Franko O, Ramirez M, Krupat E. Musculoskeletal medicine: an assessment of the attitudes and knowledge of medical students at Harvard Medical School. Acad Med. 2007:82(5):452-7.

24. Skelley NW, Tanaka MJ, Skelley LM, LaPorte DM. Medical student musculoskeletal education: an institutional survey. J Bone Joint Surg Am. 2012;94(19):e146 (1-7.

25. Peitzman SJ, Cuddy MM. Performance in physical examination on the USMLE step 2 clinical skills examination. Acad Med. 2015;90(2):209-13.
26. Stansfield RB, Diponio L, Craig C, Zeller J, Chadd E, Miller J, Monrad S. Assessing musculoskeletal examination skills and diagnostic reasoning of 4th year medical students using a novel objective structured clinical exam. BMC Med Educ. 2016;16(1):268-74.

27. Bonwell CC, Eison JAAL. Creating excitement in the classroom. 1991. ASHEERIC higher education reports: School of Education and Human Development, the George Washington University; Washington DC: ERIC clearinghouse on. High Educ. 2008:121.

28. Felder RM, Brent R. Active learning: an introduction. ASQ Higher Educ Brief. 2009;2:4-9.

29. Senti M, Miralles R, Bigorra J, Girvent M, Minguella J, Samso E, Solsona JF, Banos JE. A collaborative project to bridging the gap between basic and clinical teachers: the opinion of medical students. J Biomed Educ 2015, Article ID 620348, 9 pages.

30. Edmonds K, Hammond MF. How can visual arts help doctors develop medical insight? Int J Art Design Educ. 2012;31(1):78-89.

31. Shapiro J, Rucker $L$, Beck J. Training the clinical eye and mind: using the arts to develop medical students' observational and pattern recognition skills. Med Educ. 2006;40:263-8.

32. Majumder MAA. Should medical humanities be a part of the undergraduate medical curriculum? South East Asia J Public Health. 2013;2(1):68-9.

33. Kirklin D. The Centre of Medical Humanities, royal free and university college medical school, London, England. Acad Med. 2003;78:1048-53.

34. Rahman S, Majumder MAA. Is it assessment of learning or assessment for learning? South East Asia J Public Health. 2014;4(1):72-4.

35. General medical council (GMC). Tomorrow's doctors, London: GMC; 2009.

36. Kieser J, Livingstone $V$, Alison M. Professional storytelling in clinical dental anatomy teaching. Anat Sci Edu. 2008;1(2):84-9.

37. Trevor S. Healing allusions: the use of poetry in medical education. J Contemp Med Edu. 2015;3:127-33. https://doi.org/10.5455/jcme.20151030024353.

38. Shapiro J. Listening to the voices of medical students in poetry: self, patients, role-models and beyond. Interdiscip J Pract, Theory Res Educ. 2006; 19(1):17-30.

39. Baruch JM. Creative writing as a medical instrument. J Med Humanit. 2013; 34(4):459-69.

40. Dolberry AA. "General hospital": using skit writing and role playing to teach pathogenesis. J Microbiol Biol Educ. 2011;12(1):38-41.

41. McCurdy S, Schmiege C, Winter C. Incorporation of music in a food service food safety curriculum for high school students. Food protection trends, vol. 28; 2008. p. 107-14.

42. Governor D, Hall J, Jackson D. Teaching and learning science through song: exploring the experiences of students and teachers. Int J Sci Educ. 2013;35: 3117-40.

43. Grossman GD, Watson CE. The use of original music videos to teach natural history. J Nat Hist Educ Experience. 2015;9:1-7.

44. Gorbanev I, Sandra A-L, Gonzalez RA, Cortes A, Pomares A, Delgadillo V, et al. A systematic review of serious games in medical education: quality of evidence and pedagogy strategy. Med Educ Online. 2018;23(1):1438718.

45. Majumder MAA. Issues and priorities of medical education research in Asia. Ann Acad Med Singap. 2004:33:257-63.

46. Vertemati M, Rizzetto F, Vezzulli F, Sampogna G, Cassin S, Cenzato F, Elli M. Teaching anatomy in a modern medical course: an integrated approach at Vialba medical School in Milan. MedEdPublish. 2018.

47. Luursema J-M, Vorstenbosch M, Kooloos J. Steropsis, visuospatial ability and virtual reality in anatomy learning. Anat Res Int 2017. Article ID 1493135, 7 pages.

\section{Ready to submit your research? Choose BMC and benefit from:}

- fast, convenient online submission

- thorough peer review by experienced researchers in your field

- rapid publication on acceptance

- support for research data, including large and complex data types

- gold Open Access which fosters wider collaboration and increased citations

- maximum visibility for your research: over $100 \mathrm{M}$ website views per year

At BMC, research is always in progress.

Learn more biomedcentral.com/submissions 